\title{
Introduction to the Freedom of Information Special Edition: Emerging Perspectives, Critical Reflections, and the Need for Further Research
}

This Special Edition on Freedom of Information (FOI) hosts a small, but engaging and thoughtprovoking collection of papers. While it has been disappointing that,despite circulating the call for papers through a number of high profile 'alert lists' of both UK and international scope, the calls for papers did not generate a substantial groundswell of submissions and that not all of the submitted papers made it through the rigorous peer-reviewing process, the papers that were finally accepted for publication are worthy contributions to this important topic. A relatively new and under-researched area currently, it is hoped that this special edition will not only inform, but will also generate new questions and debate. It is hoped, too, that it will both inspire those already researching this topic and excite those not yet engaging with FOI to develop the longer-term research trajectories that will bring crucial depth of specialist knowledge, critical reflection, and understanding to FOI-related theorising, public policymaking, and practice. Finally, the special edition brings together a collection of papers of relevance to scholars and practitioners alike.

We are fortunate in this special edition to have empirically-based research papers from new and established scholars on the one hand, together with commentaries and contributions from a number of authoritative and high-profile practitioners and "FOI-insiders" on the other;these latter in the form of a "viewpoint essay" from Kevin Dunion, the Scottish Information Commissioner, and two highly readable and informative book reviews from Carole Ewart, The Campaign for Freedom of Information in Scotland, and Rosalind McInnes, BBC Scotland.The papers brought together in the special edition each adopt a different vantage point on Freedom of Information.

The special edition opens with the nicely polemical, but measured viewpoint essay from the Scottish Information Commissioner. Dunion asks if access to material through channels such as "the upstart Wikileaks" has "upstaged" the more formal routes encapsulated in Freedom of Information legislation and its associated structures, processes, and procedures. Acknowledging that problems arise whatever channels are employed he reflects that perhaps "an uncoordinated synergy is occurring between the various routes by which information can be secured - official inquiry, legal access and unauthorised disclosure". Noting "worrying signs of decay and antipathy" developing in relation to the sustainability and strengthening of Freedom of Information legislation, Dunion concludes in defence of peoples' "legitimate right to information".

Spence and Dinan's research paper examines Freedom of Information through the lens of Scotland's voluntary sector. The complex inter-relationship that exists between voluntary organisations and the government and public sector bodies that fund them is shown to impact on the extent to which and how voluntary organisations employ Freedom of Information in support of their activities. The authors offer 
a nuanced analysis of a deeply important aspect of Freedom of Information, for whether voluntary organisations are delivering services, engaging in public-policy development, or campaigning, their ability to access information is fundamentally important. Shedding light on the barriers to their engagement with Freedom of Information, whether real or perceived, Spence and Dinan's paper is an important contribution to the field.

Shepherd, Stevenson, and Flinn's research paper examines Freedom of Information from the perspective of records management in local government. Their research suggests that delivery of Freedom of Information is optimised in local authorities that adopt a strategic approach to information management and governance, and that bring together into one unit officers with corporate responsibility for Freedom of Information and records management.Counter-intuitively, they found that as records management is delivered more effectively there can be a detrimental impact for requestors of information. Thus, as retention schedules are better managed,with information retained and disposed of according to established protocols, so the pool of information that is available for request can diminish.

The special edition closes with two book reviews. Book reviews can be fairly dry reads, on occasion. These two are quite the opposite, and as well as being quite delightful 'reads', they are also substantial in the insights conveyed. Ewart's review provides a well considered and valuable set of insights into Hazell et al.'s recently published "The Impact of the Freedom of Information Act on Central Government in the UK - Does FOI Work?'McInnes offers readers of the special edition an equally well balanced and valuable set of reflections on Brooke's "The Silent State: Secrets, Surveillance and the Myth of British Democracy".

Finally, I would like to thank the Editor-in-Chief of Information Polity: the International Journal of Governance and Democracy in the Information Age for the opportunity to contribute this Special FOI Edition. I would also like to thank his team for their support and patience as the edition was brought to completion. Special thanks go to the reviewers who generously gave their time to undertake the vital peer-reviewing process. Finally, I would also like to thank the authors whose combined labours have brought us lively and thought-provoking pieces in the form of theviewpoint essay, the research-based articles, and the book reviews. Here, I think that a particular note of acknowledgement is in order in respect of Kate Spence, a doctoral student and co-author of one of the papers. It is a tribute to her professionalism that, despite suffering a serious illness in the course of submitting to the special edition, she remained committed to this particular task in hand.

\section{Dr. Eleanor Burt}

Editor Freedom of Information Special Edition

School of Management,

University of St Andrews, Scotland 